\title{
ANÁLISE QUANTITATIVA DO DESEMPENHO ACADÊMICO DAS TURMAS DE PROJETO E CONSTRUÇÃO DA INFRAESTRUTURA VIÁRIA NO CONTEXTO PRESENCIAL E DA PANDEMIA DE COVID-19
}

DOI: 10.37702/2175-957X.COBENGE.2021.3695

BRUNO CAVALCANTE MOTA - bruno86925@gmail.com

UNIVERSIDADE FEDERAL DO CEARÁ

Rua Padre Alzir Sampaio 371

60355-260 - Fortaleza - CE

FRANCISCO HEBER LACERDA DE OLIVEIRA - heber@det.ufc.br

UNIVERSIDADE FEDERAL DO CEARÁ

Centro de Tecnologia Bloco 703

60440-900 - Fortaleza - CE

SABRINA RODRIGUES GONCALVES - sabrinarg57@gmail.com

Universidade Federal do Ceará

Rafael Dantas 2236

60830-585 - Fortaleza - CE

Resumo: A pandemia de Covid-19 obrigou todos os setores da sociedade a tomarem medidas preventivas. No âmbito da educação, as atividades presenciais ficaram paralisadas, permitindo que o modelo de ensino a distância abrisse caminho para a continuidade do ensino. $O$ objetivo geral deste artigo é analisar quantitativamente o desempenho acadêmico de alunos da disciplina de Projeto e Construção da Infraestrutura Viária da Universidade Federal do Ceará (UFC) e comparar os resultados do ensino presencial (2018 e 2019) e do ensino a distância (2020). Para isso, foram analisadas as notas de projetos e avaliações de forma quantitativa, por meio de parâmetros estatísticos, permitindo a análise do desempenho acadêmico dos discentes. Assim, foi possível observar que as notas do modo presencial ficaram, em sua maioria, abaixo da média adotada pela UFC para aprovação sem avaliação final, enquanto que o modo remoto permitiu que a média final da disciplina para as turmas ofertadas ficasse acima de 7,0. Como hipótese, supõe-se que a diferença percentual se refere a mudança no método de avaliar e na flexibilidade de estudos proporcionada pelo semestre desenvolvido de 
forma virtual. Contudo, não se pode afirmar que em comparação com o semestre presencial, a melhoria de notas agrega mais conhecimento aos alunos. Portanto, espera-se que os recursos utilizados possam ser utilizados em outros cenários para verificar a eficácia do aprendizado.

Palavras-chave: Engenharia Civil. Método de avaliação. Notas. Ensino remoto. 


\section{ANÁLISE QUANTITATIVA DO DESEMPENHO ACADÊMICO DAS TURMAS DE PROJETO E CONSTRUÇÃO DA INFRAESTRUTURA VIÁRIA NO CONTEXTO PRESENCIAL E DA PANDEMIA DE COVID-19}

\section{INTRODUÇÃO}

O contexto da pandemia de Covid-19 resultou na adoção de medidas de prevenção em todos os setores da sociedade. No âmbito da educação, as aulas presenciais foram paralisadas, cedendo lugar ao modo remoto de ensino para a continuidade de atividades relacionadas ao ensino e aprendizagem. Contudo, esse modelo difere da Educação à Distância $(E a D)$ visto que, na maioria das instituições de ensino, não houve ou foram deficientes a preparação, treinamento e adequação de pessoal, ferramentas e sistemas de ensino para a efetiva mudança.

Na Universidade Federal do Ceará (UFC) foram adotados três cenários: (i) aulas presenciais; (ii) aulas remotas e (iii) aulas híbridas, permitindo a junção das duas modalidades. Desde a paralisação das atividades em março de 2020, a UFC permeou apenas entre os dois últimos cenários, ocorrendo as aulas híbridas apenas em disciplinas em que a parte prática fosse indispensável presencialmente.

Com relação à autonomia do estudante em plataformas de aprendizagem EaD, Arcúrio (2008) afirma que a separação física com o professor não deve ser motivo para o não comprometimento do aluno frente a participação ativa na aula, visto que há uma maior flexibilização de atendimentos, horários e métodos de avaliação. O autor ressalta que há a necessidade de disciplina, organização, motivação, responsabilidade, avaliação, decisão e persistência perante essa autonomia, tornando-a peculiarmente democrática.

Dentre os ambientes virtuais utilizados para a realização das aulas destacam-se o Google Meet, o Google Classroom, o Microsoft Teams, o YouTube, além do Sistema Solar e do Sistema Integrado de Gestão de Atividades Acadêmicas (SIGAA) da própria UFC. Assim, com a realidade atual e a disponibilidade de ferramentas de Tecnologias de Informação e Comunicação (TIC), tornou-se possível projetar novos ambientes de ensinoaprendizagem, métodos pedagógicos e novas rotinas que contribuíssem para a continuidade das atividades educacionais. Mota et al. (2020) abordam a utilização desses ambientes de forma síncrona (Google Meet) e assíncrona (YouTube e SIGAA) em uma disciplina do curso de Engenharia Civil da UFC, mostrando os resultados positivos com relação ao aprendizado dos discentes.

Além das plataformas em que ocorriam as aulas, também foram aplicadas metodologias de ensino que tornassem as aulas mais participativas, proporcionando ao aluno o papel de agente ativo no processo de aprendizagem. Como exemplos, cita-se a Aprendizagem Baseada em Jogos (ABJ) em que ferramentas como o Kahoot, Socrative e Plickers são utilizadas e a Aprendizagem Baseada em Projetos (ABP) na qual os professores trazem casos práticos para aplicação com os estudantes por meio de projetos.

Para Morán (2015), desafios planejados possibilitam a mobilização de competências junto aos alunos, pois exigem que eles pesquisem, avaliem situações, façam escolhas e assumam riscos, aprendendo pela descoberta e caminhando do simples para o complexo. Dessa forma, conhecer o nível de conhecimento dos alunos e como melhorá-lo é fundamental para a efetividade do aprendizado.

Contudo, na maioria das vezes os alunos possuem dificuldade de perceber o quanto aprenderam. Posto isso, uma das formas de quantificar essa aprendizagem é por meio da 
atribuição de notas às avaliações e trabalhos que os discentes desenvolvem durante determinada disciplina. Diante do exposto, o objetivo geral deste artigo é analisar quantitativamente o desempenho acadêmico dos alunos da disciplina de Projeto e Construção da Infraestrutura Viária (PCIV), do curso de Engenharia Civil da UFC, comparando os resultados do ensino presencial (em 2018 e 2019) e do ensino remoto (2020).

\section{ESTUDO DE CASO}

A disciplina de Projeto e Construção da Infraestrutura Viária (PCIV) integra a matriz curricular do curso de Engenharia Civil da UFC, sendo ofertada no 6ํㅗ semestre, com 64 horas ministradas de forma teórica, além de atividades práticas extraclasse como a execução de um projeto geométrico e de terraplenagem completo. A ementa possibilita que os alunos sejam capazes de (i) projetar e calcular os elementos geométricos do traçado de uma rodovia, (ii) conhecer as etapas de construção da terraplenagem e (iii) gerir os custos e produtividade de pessoal, máquinas e equipamentos do processo de projeto de uma via.

Historicamente, a disciplina de PCIV é ofertada em três turmas de até 40 alunos. Anteriormente ao semestre 2018.2, cada turma possuía um professor específico. Contudo, a partir de 2018.2, os três professores passaram a dividir a ementa entre si conforme os três pontos destacados no parágrafo anterior e ministraram o conteúdo da mesma forma para as três turmas. O Gráfico 1 apresenta a quantidade ofertada de vagas e a de alunos matriculados em cada turma nos semestres 2018.2, 2019.2 e 2020.2.

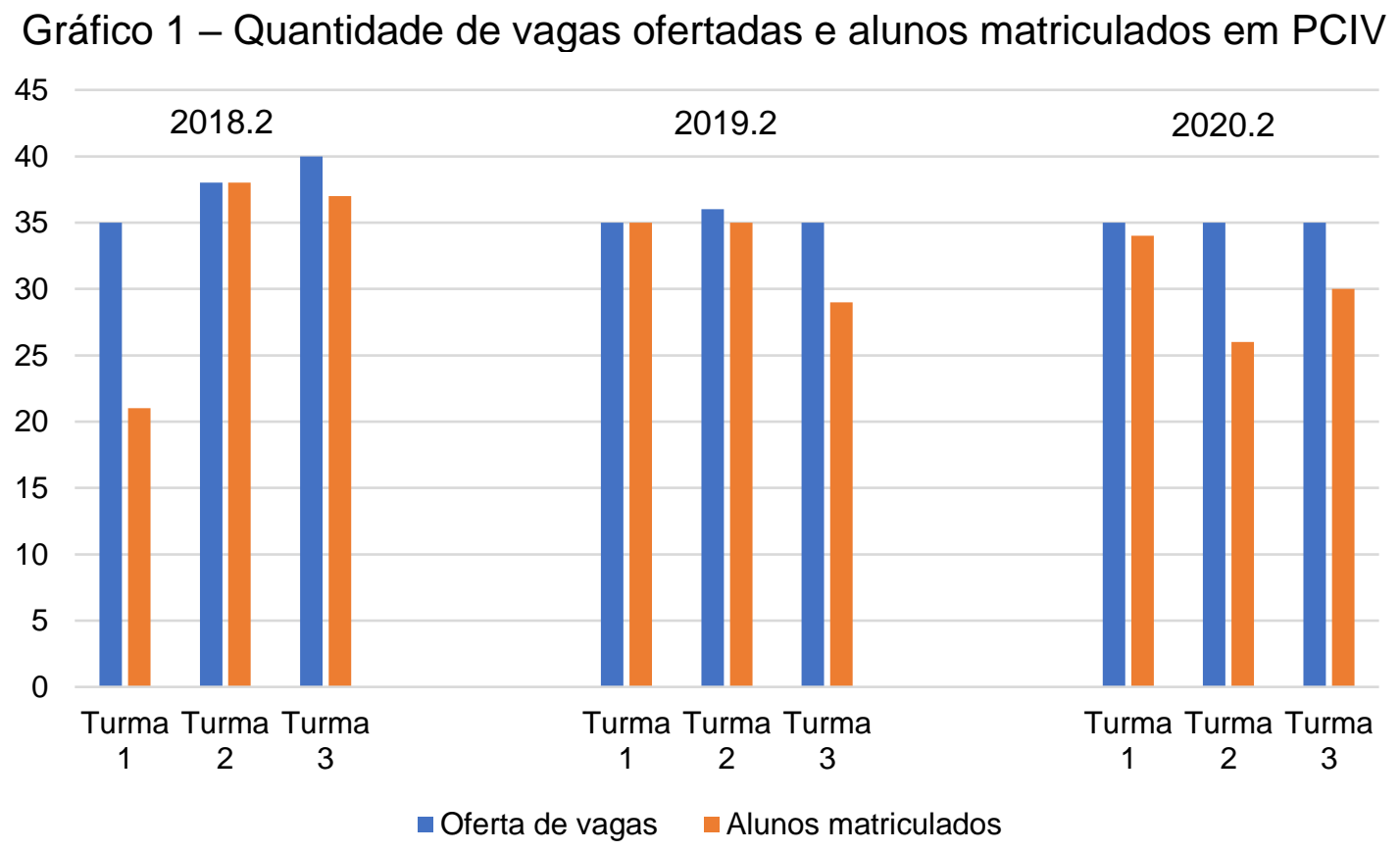

Fonte: Os autores (2021)

Dessa forma, a escolha pela turma poderia ser baseada apenas na questão do horário, visto que a ementa, a metodologia e os professores eram os mesmos para todas as turmas. Os dias de oferta foram quarta-feira e sexta-feira, com os horários de 10:0012:00h, 14:00-16:00h e de 16:00-18:00h para as turmas 1, 2 e 3, respectivamente, para ambos os semestres analisados neste artigo.

Quanto à modalidade de ensino, os semestres 2018.2 e 2019.2 ocorreram totalmente de forma presencial, enquanto que o 2020.2 foi todo ministrado de forma remota por meio 
de aulas síncronas no Google Meet, sendo possível aos alunos reverem as aulas gravadas no canal do YouTube criado para auxiliá-los. Quanto ao método de avaliação, em 2018.2 foram realizadas 3 avaliações parciais, uma em cada etapa da disciplina e o projeto de uma rodovia, dividido em duas partes (projeto geométrico e projeto de terraplenagem). Em 2019.2 ocorreu a mesma divisão de avaliações, contudo houve o incremento de mais uma parte no trabalho prático relativo à terceira etapa da disciplina, o projeto de custos. A média final nos dois semestres mencionados era composta de $60 \%$ da média das avaliações parciais e $40 \%$ da média dos projetos.

Contudo, em 2020.2 com o modo remoto, as avaliações parciais foram divididas em testes aplicados no decorrer do semestre. Na primeira parte foram aplicados 4 testes, 3 na segunda e na terceira parte, sendo excluída a menor nota de ambas as etapas. Quanto ao projeto, foi dividido em geométrico e de terraplenagem, conforme 2018.2. A média final da disciplina foi obtida da mesma forma que nos semestres anteriores, sendo $60 \%$ da média final dos testes e $40 \%$ dos projetos.

Relativo aos critérios de aprovação, os alunos que obtiveram média final (MF) acima de 7,0 foram aprovados direto, enquanto que os entre 7,0 e 4,0 foram submetidos a uma Avaliação Final (AF), obtendo aprovação ao atingirem média de 5,0 ((AF+MF)/2). Ficaram reprovados aqueles com MF abaixo de 4,0.

\section{MÉTODO DE PESQUISA}

O método de pesquisa deste trabalho baseou-se na análise quantitativa das notas das avaliações parciais (AP) e dos projetos $(\mathrm{P})$ desenvolvidos pelos alunos. Essa análise consistiu da obtenção de parâmetros estatísticos como média, mediana, $1^{\circ}$ e $3^{\circ}$ quartis, desvio padrão, coeficiente de variação, valor mínimo $\left(X_{\min }\right)$ e valor máximo $\left(X_{\text {máx }}\right)$ para as três turmas de cada ano.

Posterior a essa análise, foram comparados os resultados de média final (MF) com diferença percentual em relação ao semestre 2020.2. Essa análise ocorreu por meio da consideração da MF de todas as turmas, separadas por semestre. Como no semestre remoto não houve a aplicação de avaliações parciais de forma equivalente aos semestres anteriores, foi utilizada a média dos testes como AP1, AP2 e AP3 em cada etapa.

Com posse dos diferenciais de porcentagem, foi realizada uma análise com base na experiência dos semestres anteriores e do semestre remoto, ressaltando os pontos que possivelmente contribuíram para os resultados obtidos. A Figura 1 resume a metodologia utilizada neste trabalho.

Figura 1 - Resumo da metodologia utilizada
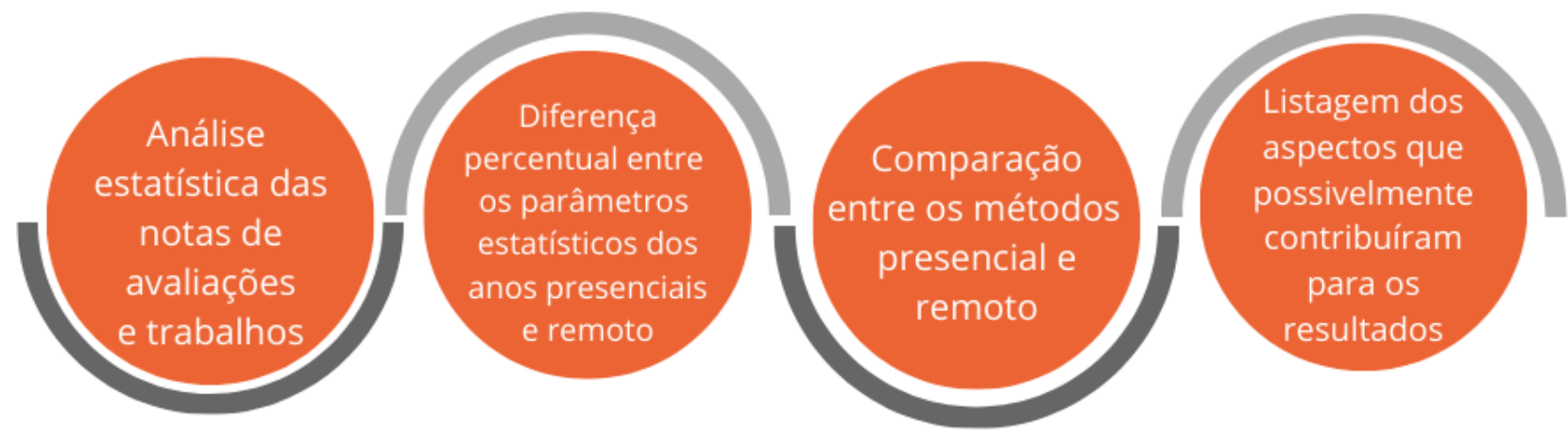

Fonte: Os autores (2021) 


\section{$4 \quad$ RESULTADOS E DISCUSSÕES}

As notas das avaliações e trabalhos foram computadas em planilhas no Excel, divididas por turmas e semestre de oferta. Para cada uma das notas foram calculados os parâmetros estatísticos e os resultados estão expostos nos Quadros 1, 2 e 3 para as 3 turmas do semestre 2018.2.

Quadro 1 - Parâmetros estatísticos da Turma 1 (2018.2)

\begin{tabular}{|c|c|c|c|c|c|c|}
\hline Estatística & AP1 & AP2 & AP3 & P1 & P2 & MF \\
\hline $\mathrm{n}$ & 20 & 20 & 20 & 20 & 20 & - \\
\hline Média & 7,2 & 4,7 & 5,9 & 8,4 & 8,1 & 6,9 \\
\hline $1^{\circ}$ quartil & 6,0 & 3,5 & 4,9 & 8,4 & 7,8 & 6,5 \\
\hline $3^{\circ}$ quartil & 8,5 & 5,3 & 7,2 & 9,0 & 9,0 & 7,5 \\
\hline Mediana & 7,5 & 4,3 & 6,0 & 9,0 & 8,5 & 7,0 \\
\hline Desvio Padrão & 1,8 & 2,5 & 2,2 & 1,9 & 2,0 & 1,7 \\
\hline Coeficiente de Variação (\%) & 25,0 & 53,2 & 37,3 & 22,6 & 24,7 & 24,6 \\
\hline$X_{\min }$ & 2,5 & 0,0 & 0,0 & 0,0 & 0,0 & 0,5 \\
\hline$X_{\text {máx }}$ & 10,0 & 10,0 & 10,0 & 9,9 & 10,0 & 9,9 \\
\hline
\end{tabular}

Fonte: Os autores (2021).

Quadro 2 - Parâmetros estatísticos da Turma 2 (2018.2)

\begin{tabular}{|c|c|c|c|c|c|c|}
\hline Estatística & AP1 & AP2 & AP3 & P1 & P2 & MF \\
\hline $\mathrm{n}$ & 38 & 38 & 38 & 38 & 38 & - \\
\hline Média & 6,1 & 5,1 & 6,6 & 7,8 & 6,4 & 6,4 \\
\hline $1^{\circ}$ quartil & 5,5 & 3,6 & 6,0 & 8,1 & 6,1 & 5,4 \\
\hline $3 \%$ quartil & 7,5 & 7,0 & 7,9 & 9,4 & 9,0 & 7,7 \\
\hline Mediana & 6,5 & 5,2 & 7,5 & 8,7 & 8,7 & 7,0 \\
\hline Desvio Padrão & 2,4 & 2,6 & 2,3 & 2,9 & 3,7 & 2,1 \\
\hline Coeficiente de Variação (\%) & 39,3 & 51,0 & 34,8 & 37,2 & 57,8 & 32,8 \\
\hline$X_{\min }$ & 0,0 & 0,0 & 0,0 & 0,0 & 0,0 & 0,0 \\
\hline$X_{\text {máx }}$ & 10,0 & 9,4 & 10,0 & 9,9 & 10,0 & 8,8 \\
\hline
\end{tabular}

Fonte: Os autores (2021)

Quadro 3 - Parâmetros estatísticos da Turma 3 (2018.2)

\begin{tabular}{|c|c|c|c|c|c|c|}
\hline Estatística & AP1 & AP2 & AP3 & P1 & P2 & MF \\
\hline n & 37 & 37 & 37 & 37 & 37 & - \\
\hline Média & 7,9 & 6,6 & 7,0 & 9,0 & 9,2 & 7,9 \\
\hline 1o quartil & 7,0 & 5,7 & 6,3 & 8,6 & 9,0 & 7,7 \\
\hline 3o quartil & 9,0 & 7,3 & 8,2 & 9,4 & 9,4 & 8,2 \\
\hline Mediana & 8,0 & 6,6 & 7,1 & 9,1 & 9,3 & 7,9 \\
\hline Desvio Padrão & 1,6 & 1,3 & 1,7 & 0,7 & 0,6 & 0,5 \\
\hline Coeficiente de Variação (\%) & 20,3 & 19,7 & 24,3 & 7,8 & 6,5 & 6,3 \\
\hline Xmin $_{\text {X }}$ & 3,0 & 3,9 & 0,0 & 7,3 & 7,5 & 6,2 \\
\hline máx & 10,0 & 9,2 & 9,5 & 9,9 & 10,0 & 9,1 \\
\hline
\end{tabular}

Fonte: Os autores (2021)

Com relação à média das avaliações, a AP2 foi a que apresentou o valor mais baixo, não ultrapassando 4,7 para a Turma 1. As médias dos projetos das turmas 1 e 3 foram satisfatórias, enquanto que para a Turma 2, no P2 a média ficou abaixo da adotada como 
parâmetro de aprovação direta. Quanto à MF, a turma com melhor desempenho foi a 3, visto que ficou acima de 7,0, seguida das turmas 1 e 2 , respectivamente.

O primeiro quartil permitiu constatar que para a Turma 3 , apenas $25 \%$ dos alunos estavam abaixo da média adotada como critério de aprovação, sendo que o mesmo não ocorreu nas demais turmas e avaliações parciais. O terceiro quartil da Turma 1 para a AP2 demonstrou que $75 \%$ dos alunos estavam abaixo de 5,3 , o que pode significar que 0 desempenho não foi satisfatório.

O desvio padrão e o coeficiente de variação foram relativamente baixos para a Turma 3 quando analisados para os projetos. Porém, a Turma 2 apresentou coeficiente de variação de $57,8 \%$ para o P2. Ao analisar as avaliações, esse parâmetro chegou a $51 \%$ para a AP2, sendo ainda mais crítico para a Turma 1, com 53,2\%.

Foi possível observar ainda que a Turma 2 apresentou nota zero em todas as avaliações e projetos como nota mínima, repetindo-se de forma quase semelhante para a Turma 1, excluindo apenas a AP1. A Turma 3, no geral, foi a que apresentou os melhores resultados dos parâmetros analisados. Como situação de número de reprovações, o quantitativo foi o seguinte: (i) Turma 1 com uma reprovação; (ii) Turma 2 com cinco reprovações e (iii) Turma 3 com nenhuma reprovação. Esses números condizem com as análises estatísticas discutidas anteriormente.

A mesma análise foi realizada para as turmas do semestre 2019.2, com a diferença de que no referido semestre foi incluindo o Projeto de Custos (P3) como uma das notas. Os Quadros 4, 5 e 6 apresentam os resultados para as turmas 1, 2 e 3, respectivamente.

Quadro 4 - Parâmetros estatísticos da Turma 1 (2019.2)

\begin{tabular}{|c|c|c|c|c|c|c|c|}
\hline Estatística & AP1 & AP2 & AP3 & P1 & P2 & P3 & MF \\
\hline N & 35 & 35 & 35 & 35 & 35 & 35 & - \\
\hline Média & 5,3 & 5,0 & 6,6 & 7,6 & 7,6 & 7,3 & 6,4 \\
\hline $1^{\circ}$ quartil & 2,7 & 2,6 & 5,5 & 6,8 & 7,1 & 5,9 & 5,2 \\
\hline $3^{\text {o quartil }}$ & 7,5 & 6,9 & 8,7 & 8,0 & 8,3 & 8,5 & 7,5 \\
\hline Mediana & 6,0 & 5,9 & 7,5 & 7,7 & 8,1 & 7,9 & 6,5 \\
\hline Desvio Padrão & 2,9 & 2,7 & 2,8 & 0,9 & 1,7 & 1,4 & 1,5 \\
\hline Coeficiente de Variação (\%) & 54,7 & 54,0 & 42,4 & 11,8 & 22,4 & 19,2 & 23,4 \\
\hline Xmin $_{\text {Xmáx }}$ & 0,0 & 0,0 & 0,0 & 6,0 & 0,0 & 4,8 & 3,0 \\
\hline & 10,0 & 9,2 & 9,8 & 9,0 & 9,5 & 9,0 & 8,7 \\
\hline
\end{tabular}

Fonte: Os autores (2021)

Quadro 5 - Parâmetros estatísticos da Turma 2 (2019.2)

\begin{tabular}{|c|c|c|c|c|c|c|c|}
\hline Estatística & AP1 & AP2 & AP3 & P1 & P2 & P3 & MF \\
\hline $\mathrm{n}$ & 35 & 35 & 35 & 35 & 35 & 35 & - \\
\hline Média & 5,4 & 7,0 & 5,1 & 7,7 & 7,1 & 8,4 & 6,6 \\
\hline 1o quartil $^{\circ}$ quartil & 4,3 & 6,5 & 4,3 & 6,8 & 6,9 & 7,9 & 6,1 \\
\hline Mediana & 6,8 & 8,4 & 6,3 & 9,4 & 9,4 & 9,9 & 7,5 \\
\hline Desvio Padrão & 5,5 & 7,5 & 5,0 & 8,3 & 8,6 & 8,4 & 6,6 \\
\hline Coeficiente de Variação (\%) & 2,0 & 2,4 & 2,0 & 2,7 & 3,4 & 1,9 & 1,0 \\
\hline Xmin $_{\text {Xáx }}$ & 0,0 & 34,3 & 39,2 & 35,1 & 47,9 & 22,6 & 15,1 \\
\hline máx & 9,0 & 10,0 & 0,0 & 0,0 & 0,0 & 0,0 & 4,4 \\
\hline
\end{tabular}

Fonte: Os autores (2021) 
Quadro 6 - Parâmetros estatísticos da Turma 3 (2019.2)

\begin{tabular}{|c|c|c|c|c|c|c|c|}
\hline Estatística & AP1 & AP2 & AP3 & P1 & P2 & P3 & MF \\
\hline $\mathrm{n}$ & 29 & 29 & 29 & 29 & 29 & 29 & - \\
\hline Média & 5,8 & 6,9 & 7,8 & 7,5 & 8,9 & 9,0 & 7,5 \\
\hline 1ํ quartil $^{\text {o }}$ quartil & 4,0 & 5,9 & 7,5 & 6,5 & 8,8 & 8,4 & 7,1 \\
\hline Mediana & 8,0 & 8,4 & 9,0 & 8,8 & 9,5 & 9,9 & 8,0 \\
\hline Desvio Padrão & 5,8 & 6,7 & 8,5 & 8,4 & 9,1 & 9,6 & 7,6 \\
\hline Coeficiente de Variação (\%) & 2,4 & 1,7 & 1,9 & 1,9 & 1,0 & 1,1 & 1,0 \\
\hline Xmin $_{\text {Xáx }}$ & 1,5 & 24,6 & 24,4 & 25,3 & 11,2 & 12,2 & 13,3 \\
\hline ma,0 & 2,5 & 3,3 & 6,1 & 6,0 & 5,1 \\
\hline
\end{tabular}

Fonte: Os autores (2021)

De forma análoga, realizou-se a discussão dos dados apresentados para as turmas 1 , 2 e 3 de 2019.2, sendo observado inicialmente que, a partir da MF, a turma que apresentou o melhor resultado foi a 3, do mesmo modo que em 2018.2, sendo a única a ficar acima da média adotada pela UFC como requisito de aprovação sem Avaliação Final (AF). Seguindo o mesmo padrão, a menor média entre as avaliações parciais foi identificada na AP2 da Turma 1, não ultrapassando o valor de 5,0. As médias dos projetos ficaram acima de 7,0 para todas as três etapas e três turmas, sendo um desempenho mais satisfatório quantitativamente quando comparado aos resultados de 2018.2.

O primeiro quartil para a AP1 e AP2 da Turma 1 foi considerado insatisfatório (abaixo de 4,0 ), em que $25 \%$ dos alunos ficaram com notas abaixo de 2,7 e 2,6 para as referidas avaliações, respectivamente. Quanto ao terceiro quartil, a Turma 3 apresentou os melhores resultados, em que $25 \%$ dos alunos ficaram acima de 8,0 (oito) para as três avaliações, ressaltando que para a AP3 esse parâmetro ficou acima de 9,0 (nove).

Os coeficientes de variação e desvio padrão ficaram relativamente altos para ambas as turmas. Contudo, a Turma 2 novamente apresentou destaque, chegando a uma variação de 47,9\% para o P2. A Turma 1 também foi crítica quanto a esse parâmetro, apresentando um coeficiente de variação de $54,7 \%$ para a AP1 e $54 \%$ para a AP2, mostrando que 0 conjunto de notas não é homogêneo. Os desvios padrões mostram que as notas da Turma 1 destoam de, aproximadamente, 3 pontos com relação à média. Esses valores são menores para as turmas 2 e 3 , ficando na faixa de 2 pontos.

Os valores mínimos permitiram identificar que nenhum aluno zerou avaliações ou projetos na Turma 3. Contudo, a situação não se repete para as turmas 1 e 2 , em que para a última, a AP2 foi a única não zerada, mas apresentou nota mínima de 0,6 pontos. Dessa forma, observou-se que a Turma 3 foi a que apresentou os melhores resultados quando analisados os parâmetros estatísticos.

Quanto às reprovações, apenas a Turma 1 apresentou, com um total de duas. Por outro lado, a Turma 2 teve mais de $50 \%$ dos alunos em situação de AF, por terem apresentado média final abaixo de 7,0, enquanto que para a Turma 3 apenas 5 dos 29 alunos encontraram-se nessa situação.

Por fim, foram analisados os dados estatísticos para as turmas 1, 2 e 3 de 2020.2, ofertadas de modo remoto. Como ressaltado, as notas de AP1, AP2 e AP3 representam as médias dos testes aplicados. No referido semestre não houve a aplicação do P3. Nos Quadros 7, 8 e 9 são expostos os parâmetros analisados. 
28 a 30 de SETEMBRO

Quadro 7 - Parâmetros estatísticos da Turma 1 (2020.2)

\begin{tabular}{|c|c|c|c|c|c|c|}
\hline Estatística & AP1 & AP2 & AP3 & P1 & P2 & MF \\
\hline $\mathrm{n}$ & 34 & 34 & 34 & 34 & 34 & 34 \\
\hline Média & 8,3 & 7,9 & 9,5 & 8,6 & 8,6 & 8,6 \\
\hline $1^{\circ}$ quartil & 7,4 & 6,7 & 9,0 & 7,9 & 8,1 & 8,2 \\
\hline $3^{\circ}$ quartil & 9,3 & 9,3 & 10,0 & 9,6 & 9,2 & 8,9 \\
\hline Mediana & 8,7 & 8,1 & 10,0 & 9,1 & 8,5 & 8,4 \\
\hline Desvio Padrão & 1,3 & 1,5 & 0,8 & 1,2 & 0,8 & 0,6 \\
\hline Coeficiente de Variação (\%) & 15,7 & 19,0 & 8,4 & 14,0 & 9,3 & 7,0 \\
\hline$X_{\min }$ & 5,3 & 4,1 & 7,0 & 5,8 & 6,5 & 7,0 \\
\hline$X_{\text {máx }}$ & 10,0 & 10,0 & 10,0 & 10,0 & 9,7 & 9,8 \\
\hline
\end{tabular}

Fonte: Os autores (2021)

Quadro 8 - Parâmetros estatísticos da Turma 2 (2020.2)

\begin{tabular}{|c|c|c|c|c|c|c|}
\hline Estatística & AP1 & AP2 & AP3 & P1 & P2 & MF \\
\hline $\mathrm{n}$ & 26 & 26 & 26 & 26 & 26 & 26 \\
\hline Média & 7,8 & 8,0 & 9,1 & 8,0 & 7,8 & 8,1 \\
\hline 1oquartil $^{\circ}$ quartil & 7,2 & 7,3 & 8,4 & 7,0 & 7,9 & 7,7 \\
\hline Mediana & 9,3 & 9,2 & 10,0 & 8,6 & 9,0 & 8,9 \\
\hline Desvio Padrão & 8,7 & 8,4 & 9,6 & 8,2 & 8,5 & 8,5 \\
\hline Coeficiente de Variação (\%) & 2,4 & 2,1 & 1,1 & 1,1 & 1,9 & 1,1 \\
\hline X $_{\text {min }}$ & 0,8 & 26,3 & 12,1 & 13,8 & 24,4 & 13,6 \\
\hline Xmáx $^{-}$ & 10,0 & 0,0 & 6,2 & 6,3 & 4,1 & 5,1 \\
\hline
\end{tabular}

Fonte: Os autores (2021)

Quadro 9 - Parâmetros estatísticos da Turma 3 (2020.2)

\begin{tabular}{|c|c|c|c|c|c|c|}
\hline Estatística & AP1 & AP2 & AP3 & P1 & P2 & MF \\
\hline $\mathrm{n}$ & 30 & 30 & 30 & 30 & 30 & 30 \\
\hline Média & 6,9 & 7,3 & 9,5 & 7,5 & 8,4 & 7,9 \\
\hline $1^{\circ}$ quartil & 5,9 & 6,3 & 9,2 & 5,8 & 8,4 & 7,3 \\
\hline $3 \%$ quartil & 8,7 & 8,6 & 10,0 & 9,6 & 9,3 & 8,9 \\
\hline Mediana & 7,4 & 7,6 & 9,9 & 7,5 & 8,9 & 8,0 \\
\hline Desvio Padrão & 2,5 & 1,6 & 0,7 & 2,0 & 1,4 & 1,1 \\
\hline Coeficiente de Variação (\%) & 36,2 & 21,9 & 7,4 & 26,7 & 16,7 & 13,9 \\
\hline$X_{\min }$ & 0,0 & 3,7 & 7,6 & 3,5 & 4,6 & 5,7 \\
\hline$X_{\text {máx }}$ & 9,9 & 9,8 & 10,0 & 9,8 & 10,0 & 9,6 \\
\hline
\end{tabular}

Fonte: Os autores (2021)

Inicialmente ressalta-se a média da AP3 para as três turmas, que ficaram acima de 9,0. Ainda, para as outras AP, apenas a AP1 da Turma 1 apresentou valor abaixo de 7,0. Esse é o melhor resultado de avaliações entre os três cenários avaliados $(2018,2019$ e 2020). Outro destaque é relativo à $M F$, que ficou acima de 7,0 nas três turmas, apresentando rendimento satisfatório. Diferentemente dos cenários presenciais, a Turma 3 foi a que apresentou a menor média para todos os casos de média, exceto a AP3.

Os resultados do primeiro e terceiro quartil foram bastante elevados para a Turma 2. Cerca de $75 \%$ dos alunos ficaram com nota acima de 7,0 nas AP1 e AP2 e 8,0 na AP3. A Turma 3 foi a que apresentou os menores resultados para esse parâmetro. Também é 
válido ressaltar que, no modo remoto, a AP1 apresentou resultados menos satisfatórios, diferentemente dos cenários presenciais em que a AP2 possuía essa tendência.

Os desvios padrões também foram menores que os observados na oferta presencial, sendo o maior de 2,5 na AP1 da Turma 2. O coeficiente de variação também sofreu redução, principalmente nas notas relativas aos projetos. Outro ponto positivo foi a baixa ocorrência de notas zero. Ocorreram apenas na AP1 para as turmas 2 e 3 e na AP3 para a Turma 2. A Turma 1 não apresentou notas zero em nenhuma das avaliações e projetos.

No tocante à reprovação, não houve ocorrência em nenhuma das turmas. Inclusive, na Turma 1 todos os alunos foram aprovados diretamente (com média acima de 7,0), sem a necessidade de realização de Avaliação Final. Esse cenário não foi observado em nenhuma das outras turmas do modo presencial. Assim, tanto por parâmetros estatísticos quanto por índice de reprovação, a Turma 1 foi a que apresentou os melhores resultados. Dessa forma, o Quadro 10 apresenta as diferenças percentuais dos parâmetros estatísticos relativos à MF de cada semestre transcorrido presencialmente com relação ao semestre 2020.2 que ocorreu de forma remota. Os valores negativos representam que para aquele parâmetro, o cenário presencial apresentou um valor mais elevado.

Quadro 10 - Diferença percentual dos parâmetros estatísticos do cenário presencial com relação ao remoto

\begin{tabular}{|c|c|c|c|c|c|c|}
\hline Estatística & $\begin{array}{c}\text { MF } \\
2018.2\end{array}$ & Dif. (\%) & $\begin{array}{c}\text { MF } \\
2019.2\end{array}$ & Dif. (\%) & $\begin{array}{c}\text { MF } \\
2020.2\end{array}$ & Dif. (\%) \\
\hline $\mathrm{n}$ & 96 & $-6,7$ & 99 & $-10,0$ & 90 & 0,0 \\
\hline Média & 7,1 & 13,4 & 6,8 & 17,1 & 8,2 & 0,0 \\
\hline $1^{\circ}$ quartil & 6,8 & 12,8 & 6,0 & 23,1 & 7,8 & 0,0 \\
\hline $3^{\circ}$ quartil & 8,1 & 9,0 & 7,7 & 13,5 & 8,9 & 0,0 \\
\hline Mediana & 7,5 & 10,7 & 7,0 & 16,7 & 8,4 & 0,0 \\
\hline Desvio Padrão & 1,8 & $-80,0$ & 1,3 & $-30,0$ & 1,0 & 0,0 \\
\hline Coeficiente de Variação (\%) & 25,3 & $-13,1$ & 19,1 & $-6,9$ & 12,2 & 0,0 \\
\hline$X_{\min }$ & 0,0 & 100,0 & 3,0 & 41,2 & 5,1 & 0,0 \\
\hline$X_{\text {máx }}$ & 9,9 & 1,0 & 9,4 & 4,1 & 9,8 & 0,0 \\
\hline
\end{tabular}

Fonte: Os autores (2021)

Como é perceptível pelo Quadro 10, os parâmetros relativos ao modo remoto apresentam um melhor desempenho quando comparados aos observados no modo presencial. A maior diferença dos parâmetros como média, mediana e quartis foram observadas no semestre 2019.2. Contudo, o maior desvio e coeficiente de variação estão presentes no semestre 2018.2, mostrando que as notas não são tão homogêneas, com uma diferença mais elevada em relação à média. $O$ semestre remoto apresentou praticamente uma homogeneidade das notas, de acordo com o baixo coeficiente de variação (abaixo de 15\%).

Logo, diante dos dados apresentados, constata-se que o semestre remoto apresentou desempenho acadêmico mais satisfatório com relação aos semestres de 2018.2 e 2019.2. Assim, levantam-se algumas hipóteses do que pode ter contribuído para essa melhora relativa às médias finais:

(i) A flexibilidade de estudos e horários proporcionada pelas aulas síncronas (via Google Meet) e a disponibilidade delas de forma assíncrona (via YouTube) no modo remoto;

(ii) A substituição das avaliações parciais por testes durante o modo remoto, incluindo a exclusão da menor nota desses em cada uma das três etapas de realização; 
(iii) A disponibilidade de conteúdos extras de forma online (nas plataformas do SIGAA e YouTube) no semestre remoto;

(iv) A possibilidade de consulta a outros materiais durante a realização dos testes aplicados no semestre 2020.2;

(v) Inserção de um terceiro trabalho no semestre 2019.2, que apresentou notas mais baixas quando comparadas aos realizados no semestre anterior e posterior.

Ressalta-se que a metodologia e conteúdo aplicada nos três cenários analisados foram as mesmas, além de que os professores também não foram substituídos, tornando possível a comparação dos três semestre com relação às notas.

\section{$5 \quad$ CONSIDERAÇÕES FINAIS}

O presente trabalho buscou analisar quantitativamente, por meio de parâmetros estatísticos, o desempenho acadêmico das turmas ofertadas da disciplina de Projeto e Construção da Infraestrutura Viária nos anos de 2018, 2019 e 2020. Além disso, foram comparadas as médias finais dos semestres presenciais com o realizado de forma remota, objetivando levantar hipóteses do que pode ter contribuído para a diferença percentual entre os valores. Foi possível identificar que a metodologia adotada no modo remoto melhorou o desempenho acadêmico dos alunos da disciplina, observado por meio da média final da disciplina. A mudança foi relativa ao ambiente (remoto), à disponibilidade das aulas (síncrona e assíncrona), aos materiais extras disponibilizados em canal do YouTube e ao formato de avaliar (substituição das avaliações parciais por testes).

Apesar dos impasses impostos durante a pandemia, notou-se uma melhora no quesito quantitativo. Contudo, não se pode afirmar que essa melhora de notas agregou mais conhecimento aos alunos quando comparado com os semestres presenciais. Assim, espera-se que futuramente os recursos utilizados possam ser utilizados no modo presencial para verificar a efetividade da aprendizagem e sejam desenvolvidas mais pesquisas abordando esse tipo de análise do desempenho acadêmico dos alunos, visto a baixa ocorrência de bibliografia relacionada ao tema.

\section{Agradecimentos}

Os autores agradecem ao CNPq pela bolsa de mestrado do primeiro autor.

\section{REFERÊNCIAS}

ARCÚRIO, Michelle Salgado Ferreira. Autonomia do aprendiz na educação a distância.

Revista Partes, v. 0, n. 0, 23 dez. 2008. Disponível em:

$<$ https://www.partes.com.br/2008/12/23/autonomia-do-aprendiz-na-educacao-a-

distancia/>. Acesso em: 18 abr. 2021.

MORÁN, José Manuel. Mudando a educação com metodologias ativas. Coleção Mídias Contemporâneas. Convergências Midiáticas, Educação e Cidadania: aproximações jovens, v. 2, 2015. Disponível em: <http://rh.unis.edu.br/wpcontent/uploads/sites/67/2016/06/Mudando-a-Educacao-com-Metodologias-Ativas.pdf>. Acesso em: 17 abr. 2021.

MOTA, Bruno Cavalcante; OLIVEIRA, Francisco Heber Lacerda de; BARROSO, Suelly Helena de Araújo. Estratégias de ensino remoto e a comparação com o Ensino presencial 
na área de engenharia de transportes. In: Congresso Brasileiro de Educação em

Engenharia, 48, 2020. Anais. Online: ABENGE, 2020.

\title{
QUANTITATIVE ANALYSIS OF THE ACADEMIC PERFORMANCE OF THE CLASSES OF PROJECT AND CONSTRUCTION OF ROAD INFRASTRUCTURE IN THE FACE- TO-FACE CONTEXT AND THE COVID-19 PANDEMIC
}

\begin{abstract}
The Covid-19 pandemic forced all sectors of society to take preventive measures. In education, classroom activities were paralyzed, allowing the distance learning model to pave the way for the continuity of education. The overall objective of this paper is to quantitatively analyze the academic performance of students in the discipline of Project and Construction of Road Infrastructure of the Federal University of Ceará (UFC) and compare the results of face-to-face teaching (2018 and 2019) and distance learning (2020). For this, project grades and assessments were analyzed in a quantitative way, by means of statistical parameters, allowing the analysis of the academic performance of the students. Thus, it was possible to observe that the grades in the face-to-face mode were mostly below the average adopted by the UFC for approval without final evaluation, while the remote mode allowed the final average of the subject for the offered classes to be above 7.0. As a hypothesis, it is assumed that the percentage difference refers to the change in the evaluation method and the flexibility of studies provided by the semester developed in a virtual way. However, it is not possible to affirm that, in comparison with the face-to-face semester, the improvement in grades adds more knowledge to the students. Therefore, it is hoped that the resources used can be used in other scenarios to verify the effectiveness of learning.
\end{abstract}

Keywords: Civil Engineering. Assessment method. Grades. Remote teaching. 